\title{
EVALUACIÓN DE LA REFORMA CURRICULAR EN EDUCACIÓN MEDIA TÉCNICO-PROFESIONAL: PERSPECTIVA DE LOS DOCENTES
}

\section{Introducción}

El propósito central de la presente publicación es dar cuenta de los alcances que tuvo la reforma de 1998 implementada en la enseñanza técnico-profesional con ocasión de la dictación del Decreto 220 que buscó adaptar el currículum al enfoque basado en competencias laborales. En esa perspectiva, conviene destacar que la investigación que da origen a este artículo consigna la percepción y evaluación de los docentes respecto de la reforma curricular del sector técnico profesional sancionada por el Decreto 220 de 1998.

El artículo resume los principales aspectos conceptuales que en la actualidad deben ser considerados para abordar informadamente la reflexión sobre la forma en que se implementa la Reforma Curricular en la Educación Media Técnico-Profesional (EMTP) a partir de las evidencias empíricas que proporciona el análisis de factores y vectores propuestos en el estudio.

Para abordar la reforma de 1998 se diseñó un modelo de evaluación sustentado, por una parte, en un conjunto de factores que deben considerarse para dar cuenta de los resultados de la Reforma y, por otra, en vectores asociados con capacidades que deben estar presentes en las cuarenta y seis especialidades de la EMTP. El modelo de evaluación propuesto tiene la ventaja de que se ajusta a las peculiaridades del enfoque curricular basado en competencias. Por ende, el estudio no pretendía evaluar una implementación curricular clásica que contrasta los contenidos de planes y programas de una formación convencional.

La discusión teórico conceptual permite proveer una batería de instrumentos para evaluar empíricamente aspectos relacionados con la gestión de los procesos organizacionales, que aseguran las 
condiciones adecuadas y necesarias para favorecer el logro de aprendizajes y cómo ésta se constituye en la instancia donde se genera el cambio, el mejoramiento, la innovación y la construcción del conocimiento institucional acerca del desarrollo y resultado de las propias prácticas de enseñanza-aprendizaje. Del mismo modo, este trabajo contribuye a detectar los aspectos más importantes para entender en el contexto conceptual del modelo curricular con enfoque en competencias laborales, los criterios, procedimientos y cambios que deben realizarse en la gestión de la institución educativa, para implementar adecuadamente la reforma curricular en la EMTP.

En la actualidad, en Chile el 37,1\% de la matrícula de la educación media, sin incluir la enseñanza de adultos, corresponde a EMTP y según datos de la División de Planificación y Presupuesto del Ministerio de Educación (Mineduc), en el año 2008, estaban incorporados en esta modalidad 379.115 estudiantes. La totalidad de los establecimientos corresponden a educación pública de dependencia municipal y particular que reciben subvención del Estado en sus diferentes modalidades.

Se trata de un tema de importancia social porque la cobertura de la EMTP se incrementó a un 43,4\% en el periodo 1994-2005 y éste se relaciona con la inclusión y retención de jóvenes de las familias de los quintiles más pobres (OCDE, 2004). Estas cifras muestran la alta demanda por este tipo de educación, la que presumiblemente es vista por muchas familias como una mejor opción para que sus hijos ingresen al mercado del trabajo.

A partir de la dictación del Decreto N. ${ }^{\circ} 220$ de 1998 que reforma la educación media técnica profesional en Chile, el Mineduc elaboró programas de estudios modulares para todas las especialidades y los puso a disposición de los establecimientos que no contaran con programas propios. Pese a que dicho decreto señala que tienen la facultad de elaborar planes y programas propios, un 90,6\% de los liceos de EMTP implementaron los programas oficiales (Mineduc, 2006).

Un estudio realizado recientemente concluye que un substancial número de profesores que se desempeña en el nivel técnico profesional 
no conoce aspectos de didáctica relacionada con sus especialidades, metodologías ni estilos evaluativos para poner en práctica el nuevo modelo curricular, además de la constatación de la insuficiencia de medios y equipamiento necesario para cumplir los lineamentos del programa de cada especialidad, sobre todo en los módulos que llevan a la especialización en competencias específicas (Márquez, Mena, Espinoza, Álvarez y otros, 2005).

Desde la implementación de la reforma en la EMTP hasta ahora, han egresado ocho generaciones que recibieron formación en diversas especialidades considerando las orientaciones y planteamientos de este decreto y las características particulares de este enfoque curricular definido en los programas de estudio oficiales. En este contexto, la evidencia documental muestra que no se cuenta con una sistematización para evaluar su ejecución, especialmente en relación con los recursos y la gestión organizacional requerida para conseguir aprendizajes esperados y capacidades planteadas en los perfiles de egreso para sus estudiantes, a partir de las ideas, conceptos y orientaciones asumidas en las instituciones.

La puesta en marcha de esta reforma involucra a un número significativo de estudiantes e instituciones y se relaciona directamente con la gestión asociada a temas curriculares en esquemas organizacionales, cuyas estructuras técnico-pedagógicas conducirían muy tardíamente los ajustes necesarios para producir aprendizajes.

La presente investigación comienza con un análisis conceptual sobre la implementación curricular en las instituciones de EMTP, orientado a descubrir aspectos relacionados con la gestión de procesos organizacionales que aseguren las condiciones adecuadas y necesarias para el logro de aprendizajes y cómo ésta se constituye en la instancia donde se genera el cambio, el mejoramiento, la innovación y la construcción del conocimiento institucional acerca del desarrollo y resultado de las propias prácticas de enseñanza-aprendizaje.

Se busca detectar los aspectos más importantes que permitan entender en el contexto conceptual del modelo curricular con enfoque en competencias laborales, los criterios, procedimientos y cambios que deben realizarse en la gestión institucional, para implementar 
adecuadamente la reforma curricular en EMTP, evaluando la situación actual y proponiendo estrategias para superar los déficit detectados.

El primer paso consistió en determinar las principales variables involucradas en el enfoque curricular, realizando un estudio bibliográfico que permitió configurar un contenido conceptual ordenado y sistematizado, sobre la realidad del modelo y aspectos que llevan a proponerlo como alternativa válida para la educación técnica.

La hipótesis que da inicio a esta investigación está planteada en relación con carencias y dificultades respecto del tipo de medios y recursos que utilizan los docentes de esta modalidad, para lograr aprendizajes de carácter técnico y para la formación de capacidades establecidas en perfiles de egreso de determinadas especialidades. Para esto es necesario considerar las variables que intervienen en una adecuada ejecución de la reforma curricular y las líneas de apoyo establecidas desde instancias oficiales respecto de la internalización del modelo curricular con enfoque en competencias laborales y estructura modular señaladas en los programas de estudio.

Considerando la particularidad de este enfoque curricular y las características de las instituciones de dependencia municipal, particular subvencionada y de administración delegada que lo están implementando, se espera con esta investigación aumentar la comprensión de docentes y directivos de instituciones de EMTP, así como de los policy makers y autoridades del nivel central, respecto de un proceso formativo que lleve al desarrollo de capacidades de sus estudiantes, a partir de la organización adecuada de recursos y participación de todos los involucrados.

Para avanzar en el mejoramiento de la calidad de la educación técnica es imprescindible contar con una adecuada implementación curricular, lo que implica una profunda revisión y análisis de los fundamentos del modelo curricular vigente. En esa perspectiva, se requiere establecer estrategias de solución que involucren la internalización del concepto por parte de los actores y la ejecución de innovaciones en beneficio de los estudiantes, que al realizar actividades de aprendizaje relevantes podrían adquirir capacidades 
necesarias para su desarrollo humano y una adecuada inserción laboral en el contexto del desarrollo productivo regional y nacional.

Algunas de las interrogantes que se abordaron en el estudio fueron las siguientes:

- ¿Cuáles son los factores que a partir de las evidencias empíricas que proporciona la observación de establecimientos de educación media técnico-profesional explican el tipo de trabajo que realizan en la implementación de la reforma curricular en educación técnico-profesional?

- ¿A través de qué mecanismos concretos se manifiesta la capacidad que tienen los establecimientos educacionales de las especialidades de Contabilidad y Electricidad, para apropiarse y operacionalizar conceptos y requerimientos que surgen de las transformaciones que experimenta la sociedad moderna, para mejorar la enseñanza de formación técnico profesional e indicadores de empleabilidad de la carrera?

- ¿Qué condiciones se observan y qué cambios ha efectuado el establecimiento educativo para implementar el currículum técnico profesional con enfoque en competencias laborales?

- ¿En qué medida se asemejan o diferencian los grupos de capacidades teóricas definidas como vectores en la revisión bibliográfica, con la evidencia empírica que se observa en establecimientos escolares de la EMTP?

\section{Propuesta de modelo para determinar la percepción y evaluación de la reforma en la EMTP por parte de los docentes}

La revisión bibliográfica y documental permitió identificar las principales variables involucradas o relacionadas con el modelo curricular con enfoque en competencias laborales. Sobre la base de esta información se operacionalizaron los conceptos para buscar evidencia en los liceos.

En el contexto teórico de la investigación que origina esta publicación, se ahondó en el tema de las competencias laborales (Catalano, Avolio y Sladogna, 2004; CINTERFOR, 2007; Descy y 
Tessaring, 2002; Ducci, 1997; Gallart y Jacinto, 1997; Gonzci, 1996; Kochanski, 1998; Le Boterf, 2001; Miranda, 2003; Navío, 2005) en el entendido de que dicho concepto constituye el pilar fundamental de la reforma curricular implementada desde fines de los años noventa y que ha sido motivo de diversas interpretaciones y análisis, tanto desde la perspectiva teórica como desde la práctica. En ese sentido, una definición que resume los alcances del concepto es la establecida por Bunk (1994) quien señala: "Posee competencia profesional quien dispone de los conocimientos, destrezas y aptitudes necesarios para ejercer una profesión, puede resolver los problemas profesionales de forma autónoma y flexible, y está capacitado para colaborar en su entorno profesional y en la organización del trabajo".

Específicamente, la revisión de la literatura nacional e internacional permitió identificar los cuatro grandes aspectos que aglutinan todas las variables e indicadores que dan cuenta de la implementación de una reforma curricular en esta modalidad y que para efectos de esta investigación se denominarán factores. Éstos corresponden a una forma de clasificación definida para establecer un orden en el análisis de variables, como asimismo para poder establecer relaciones que lleven a explicar la situación que se investiga.

Los factores dan cuenta de lo siguiente:

- El tipo de sociedad y características de la época de trascendentes cambios en que se sitúa el fenómeno que se quiere explicar.

- El currículum que se propone desde el Estado para superar problemas que presenta la educación técnica y que permitan el desarrollo de capacidades necesarias para una adecuada inserción laboral y prosecución de estudios superiores.

- Las institución educativa y como esta se ve afectada por cambios en el currículum en aspectos como prácticas pedagógicas y gestión necesaria para el logro de aprendizajes.

- Las políticas educativas diseñadas desde el Estado para la producción de estos cambios en el currículum y el apoyo prestado a instituciones educativas para su adecuada implementación.

A continuación se definen los factores que deben considerarse para abordar la reforma curricular, incluyendo la definición operacional 
a partir de los cuales se construyeron indicadores utilizados en el proceso de recolección de información empírica.

FACTORES

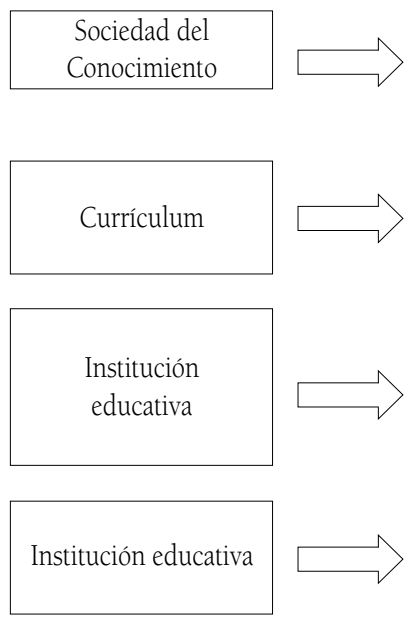

\section{CARACTERÍSTICAS}

La irrupción y desarrollo vertiginoso del conocimiento que explica el actual paradigma de sociedad en que nos desenvolvemos.

El desarrollo de capacidades que necesitan las personas para este nuevo tipo de sociedad, que lleva a renovar el currículum y sus formas de implementación.

El cambio que deben efectuar las instituciones educativas en sus prácticas y especialmente en la forma de gestión, para implementar este nuevo currículum y lograr aprendizajes en sus estudiantes.

Las políticas educativas que han llevado a esta reforma curricular y a establecer líneas de apoyo para la implementación adecuada en instituciones educativas.

Fuente: Elaboración de los autores.

El marco conceptual elaborado para entender supuestos que subyacen a la implementación curricular en instituciones de EMTP permitió identificar los aspectos más importantes respecto de criterios, procedimientos y cambios que deben realizarse en su gestión, para realizar adecuadamente la reforma curricular. Una vez definidos los aspectos relevantes, se establecieron las variables que agrupadas en cuatro factores (Sociedad del Conocimiento, Currículum, Institución Educativa y Políticas Educativas) permitieron focalizar la observación sobre la realidad de implementación curricular en las instituciones. A su vez, cada uno de los factores asociado a un conjunto de variables es operacionalizado a través de indicadores incluidos en los instrumentos, para permitir elaboración de preguntas atingentes a la investigación desarrollada en terreno. En la tabla n. ${ }^{\circ} 2.1$ se ilustra el modelo de análisis base para elaborar operacionalmente indicadores posteriormente consignados en los instrumentos. 
Tabla n. ${ }^{\circ}$ 2.1. Variables consignadas en los instrumentos.

\begin{tabular}{|l|l|}
\hline Factores & Variables \\
\hline \multirow{4}{*}{ Sociedad del conocimiento } & Cambios sociales y económicos que afectan al trabajo \\
\hline & El aprendizaje en la sociedad del conocimiento \\
\hline \multirow{4}{*}{ Currículum } & Cambios en la educación técnica \\
\hline & Concepto de competencia \\
\hline & Modelo curricular \\
\hline & Reforma curricular en la educación técnica \\
\hline \multirow{4}{*}{ Institución educativa } & Gidáctica específica para el modelo curricular \\
\hline & Escenarios de aprendizaje y su organización \\
\hline & Gestión organizacional \\
\cline { 2 - 2 } & Gestión del conocimiento \\
\hline \multirow{2}{*}{ Políticas educativas } & Perfeccionamiento de los docentes \\
\hline & Aseguramiento de la calidad \\
\hline
\end{tabular}

La revisión documental permitió, a su vez, construir un modelo de vectores para evaluar capacidades a desarrollar idealmente en cada especialidad de la EMTP. La construcción de este modelo se justificó en la medida que se necesitaba un instrumento que fuera equivalente y transversal a todas las especialidades de la enseñanza técnico-profesional. Dicho modelo se construyó a partir del análisis de capacidades planteadas en los perfiles de egreso de las cuarenta y seis especialidades existentes en la EMTP. Por una parte, el modelo permite identificar los elementos comunes a las distintas especialidades y, por otra, establecer grupos de capacidades asociadas a vectores consignados en el modelo.

La propuesta de agrupación de capacidades o vectores fue graduada en diferentes niveles, según las características del trabajo particular de cada especialidad. En ese contexto, los vectores fueron clasificados en seis niveles (asociados a distintas capacidades) y fueron generados a partir de: un análisis de las competencias definidas en el perfil profesional, las capacidades presentes en perfiles de egreso y especificaciones relacionadas con especialidades respecto del campo laboral, insumos que se manejan, procesos involucrados, equipos, instrumentos, herramientas y productos resultantes.

Los aspectos relacionados con el diseño curricular apuntan a un ámbito clave que es la determinación de capacidades, cuya construcción debe ser garantizada por el proceso formativo, a 
través del conjunto de saberes articulados que se ponen en juego, interrelacionadamente, en las actividades y situaciones de trabajo. Las capacidades, a su vez, se traducen en habilidades complejas, centradas en un saber hacer racional, organizado, planificado, integrador y creativo que se aplica en situaciones concretas, tales como: resolver problemas, elaborar proyectos, ejecutar actividades y tareas propias del desempeño profesional. Este saber hacer se fundamenta en conocimientos científicos, conocimientos técnicos, marcos valóricos y capacidades básicas. Del análisis de las capacidades que se ponen en juego para resolver las situaciones problemáticas se pueden determinar ejes y establecer contenidos relacionados con cada uno de ellos para organizarlos de acuerdo con criterios lógicos, tecnológicos, sociales y psicológicos.

Los vectores pueden ser estratificados en diferentes niveles de desempeño, según las características del trabajo específico en cada especialidad de la EMTP, los cuales se enumeran a continuación:

- Entorno laboral: capacidad de trabajar en un ambiente que posee diferentes características como cerrado, semiabierto o al aire libre, además de otras variables asociadas con la actividad productiva.

- Manejo de documentación normativa y legal: capacidad para manejar información y o documentación de distinta índole y en diferentes niveles de importancia.

- Manejo de habilidades cognitivas: capacidad para enfrentar distinto tipo de situaciones tanto en el plano personal como organizacional y que requieren de diferentes niveles de reflexión y análisis.

- Operación y uso de equipamiento tecnológico: capacidad que tienen las personas para el uso y mantenimiento de equipamiento.

- Cooperación y comunicación: capacidad para trabajar en equipo e interrelacionarse con pares, superiores y otros funcionarios de la institución para el cumplimiento de determinadas tareas organizacionales.

- Manejo de información gráfica y simbólica: capacidad para interpretar información gráfica y simbólica (información icónica, diagramas y planos), de distinto grado de complejidad. 
- Trabajo corporal y habilidades específicas: capacidad de esfuerzo físico que se puede desplegar y habilidades específicas requeridas para desempeñar cierto tipo de actividad. Mientras en algunos entornos laborales se requiere escaso esfuerzo físico y mínimas habilidades, en otros las exigencias pueden resultar ser totalmente contrapuestas.

- Seguridad y prevención de riesgos: capacidad para desempeñarse en escenarios o medios donde las normas de seguridad y prevención tienen diferentes connotaciones dependiendo por cierto del tipo de actividad o giro que desarrolle la institución o empresa.

En la figura n. ${ }^{\circ} 2.1$ se presenta un esquema, en que se pueden, con posterioridad al análisis de los perfiles de egreso de una especialidad, consignar los niveles de los vectores para las diferentes especialidades.

Figura n. ${ }^{\circ}$ 2.1. Vectores que agrupan capacidades comunes en los perfiles de egreso.

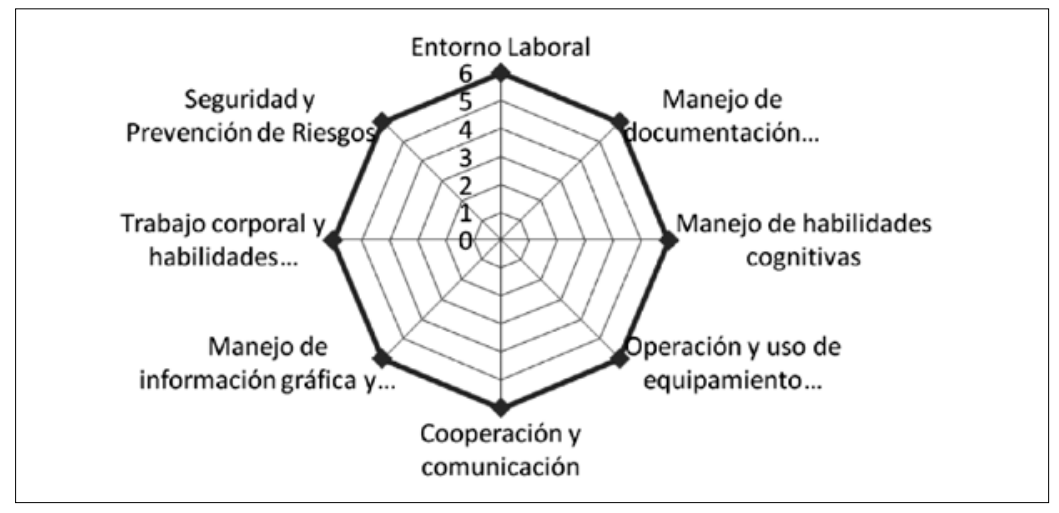

Fuente: Elaboración de los autores.

\section{Metodología}

La investigación corresponde a un estudio de caso comparado (cuyos casos son las especialidades formativas asociadas a dos sectores productivos) en cuya primera fase se genera un marco teórico a partir de una exhaustiva revisión documental que, por una parte, permitió dar cuenta del "estado del arte" y, por otra, construir el marco de referencia para identificar y definir conceptualmente los factores y las 
variables que se incluyeron en el modelo de factores y de vectores que sirvió de base para evaluar la reforma. En un segundo momento, dicho marco conceptual es operacionalizado y contrastado empíricamente con los casos estudiados considerando la información empírica que se recogió a partir de una muestra conformada por dieciséis establecimientos de enseñanza media técnico-profesional (liceos evidencia), de tres regiones del país (Quinta, Octava y Metropolitana). Cada región estuvo representada por cuatro establecimientos, dos de la especialidad de Contabilidad y dos de Electricidad.

Esta última opción se justificó considerando dos sectores productivos antagónicos y con mayor presencia regional. Consecuentemente, el estudio se concentró en dos especialidades de áreas productivas distintas. La primera del ámbito tecnológico industrial (Electricidad) y la segunda del ámbito administración y comercio (Contabilidad). De esta manera se visitaron establecimientos de las comunas de Valparaíso, Talcahuano, Concepción, Coronel, San Pedro de la Paz, Santiago, Nuñoa, San Miguel, Quinta Normal y Maipú.

Esta segunda etapa estuvo destinada a levantar información de los liceos evidencia, a través de la administración de cuestionarios aplicados a docentes de los establecimientos seleccionados en las tres regiones predefinidas. Junto a ello, se realizaron entrevistas semiestructuradas a directores, jefes de UTP y jefes de Especialidad, lo que permitió abordar aspectos relacionados con las líneas de apoyo definidas desde el Ministerio de Educación y desde el Programa Chile Califica.

Los instrumentos de medición, incluyendo el cuestionario de factores y vectores, fueron administrados a un universo de ciento setenta y dos docentes de ambas especialidades: cincuenta y cuatro de liceos municipales, ochenta de particulares subvencionados así como a treinta y ocho de liceos delegados.

Los cuestionarios, graduados por el escalonamiento de tipo Likert, fueron evaluados en términos de su validez y confiabilidad previos a su aplicación. De ahí que los ítems seleccionados e incluidos en la versión final del cuestionario consideraron dos elementos: primero, 
en cuanto a la validez, que la redacción de las preguntas estuviera ajustada a la cultura escolar de los establecimientos de enseñanza media técnico-profesional y, particularmente para las especialidades de Contabilidad y Electricidad. Segundo, la confiabilidad estadística fue medida por el Coeficiente Alpha de Cronbach, cuyo resultado proporcionó un valor del coeficiente de 0,9345, en una escala de cero a uno, vale decir, una buena confiabilidad. Por lo tanto, los indicadores usados en el cuestionario de factores y de vectores mostraron ser válidos considerando el soporte teórico y bibliográfico desde el cual se operacionalizaron y confiables desde la perspectiva estadística.

\section{Evaluación de la reforma a partir del análisis de factores}

La actualización del "estado del arte", sintetizada en el apartado que trata los aspectos conceptuales, identificó cuatro factores para evaluar la implementación de la reforma curricular basada en competencias laborales para la enseñanza media técnico-profesional, tal como se consigna en el Decreto 220: Sociedad del Conocimiento, Currículum, Institución Educativa y Política Educativa. En este sentido, conviene insistir en que los factores e indicadores que se usaron en la investigación permitieron evaluar los efectos de la Reforma desde la perspectiva de los docentes y no el contraste entre los contenidos curriculares oficiales y los curriculares dictados por el docente en aula o los aprendidos por el estudiante.

En consecuencia, la operacionalización de estos factores a indicadores concretos y directamente observables en los liceos permitió obtener una mirada evaluativa de los docentes acerca de la implementación de la reforma curricular en la EMTP en los establecimientos educacionales.

Concretamente, las respuestas proporcionadas por los docentes y jefes de especialidad de Contabilidad y Electricidad a través del cuestionario autoaplicado fueron procesadas y agrupadas en función del factor que representaban (Sociedad del Conocimiento, Currículum, Institución Educativa y Política Educativa), permitiendo construir cuatro subescalas. De igual forma, la integración de todos 
los indicadores, independientemente del factor que representaban, permitió construir una Escala General que da cuenta de la evaluación de la Reforma promovida en el Decreto 220.

Para facilitar la interpretación de los resultados, los valores obtenidos por cada indicador se agruparon en tres categorías ordinales que evidencian la valoración de la implementación de la Reforma en los establecimientos educacionales. La categoría "inadecuada" da cuenta de un liceo que, en opinión de sus docentes, no reúne o genera condiciones para su implementación. La categoría "regular" denota a uno que, desde la misma perspectiva, cuenta con condiciones modestas para llevar a cabo la Reforma, mientras que con la categoría "adecuada", se muestra un liceo en el cual los docentes evalúan de manera positiva la implementación.

Junto a lo anterior, debe considerarse que pese a que la muestra de establecimientos fue seleccionada e intencionada para buscar representar la diversidad y heterogeneidad de instituciones educativas de formación técnico-profesional, es necesario advertir que el análisis de los resultados que se presentarán a continuación no pueden ser extrapolados estadísticamente al conjunto de establecimientos TP del país, pues se desconoce el error muestral. Si bien las evidencias de este estudio dan cuenta de dos especialidades (Electricidad y Contabilidad), el modelo de análisis por su versatilidad puede ser aplicable a las cuarenta y seis especialidades de la EMTP.

Resultados de la evaluación a partir de la aplicación del Modelo de Factores

En el gráfico n. ${ }^{\circ} 4.1$ se muestra el porcentaje que obtuvo cada una de las tres categorías en las que se ha traducido la implementación de la reforma curricular en los liceos técnico-profesionales. Del mismo modo, estos valores corresponden a las puntuaciones de la Escala General de Implementación de la Reforma, elaborada sobre la base de la ponderación de todos los indicadores incluidos en el cuestionario, independientemente del factor al cual se relacionan.

Un 4,7\% de los docentes encuestados sostiene que en sus instituciones educativas la implementación de la Reforma de la 
Enseñanza Media Técnico-Profesional puede calificarse de inadecuada, mientras que un $37,2 \%$ indica que en sus establecimientos escolares se lleva a cabo de manera adecuada. Por su parte, un 58,1\% de los docentes estima que la implementación de dicha Reforma en la EMTP puede catalogarse sólo como regular. Estos datos permiten sostener que casi dos tercios de los encuestados opinan que en sus liceos no se estaría implementando adecuadamente la Reforma impulsada por el Decreto 220.

Gráfico n. ${ }^{\circ}$ 4.1. Implementación de la reforma curricular.

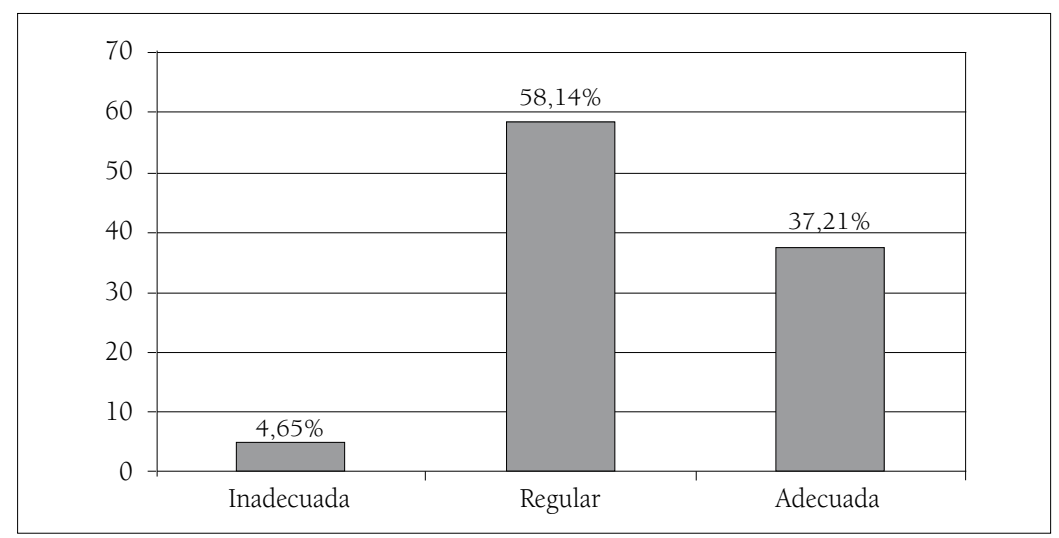

En el gráfico n. ${ }^{\circ} 4.2$ se da cuenta de las representaciones porcentuales de puntuaciones obtenidas por la subescala "Sociedad del Conocimiento". Dicho de otro modo, se muestra la implementación de la reforma curricular en EMTP desde la perspectiva de la incorporación que el establecimiento educativo hace del flujo de información y conocimiento que proviene de las transformaciones sociales, económicas y culturales que vive la sociedad contemporánea. 
Gráfico n. ${ }^{0}$ 4.2. Factor Sociedad del Conocimiento.

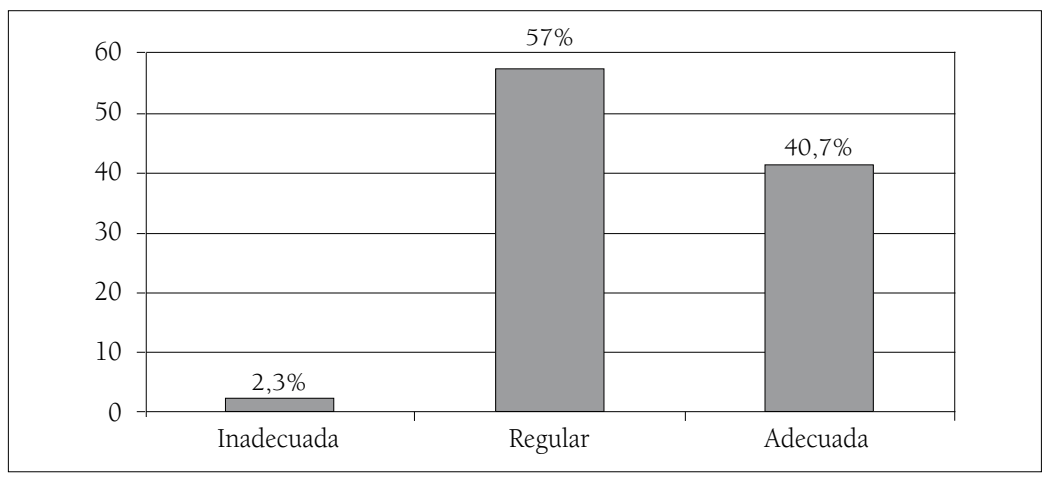

Según estos datos, en el caso del factor "Sociedad del Conocimiento", la situación de la implementación varía levemente en relación con la observada en la escala general. No obstante, el porcentaje de docentes que opta por la categoría "adecuada" al momento de responder la encuesta aumenta en prácticamente tres puntos porcentuales.

Respecto de los datos de la subescala "Factor Curricular" la información proporcionada por el gráfico n. ${ }^{\circ} 4.3$ muestra una leve disminución en las percepciones de los docentes respecto de lo observado en el factor "Sociedad del Conocimiento" y en la escala general. De hecho, el porcentaje de docentes identificados con la categoría "adecuada" disminuye a un 36\%, aumentando inversamente la proporción de docentes ubicados en la categoría "regular".

Los porcentajes de este factor indican que la categoría "adecuada" disminuyó en prácticamente cinco puntos porcentuales respecto del factor "Sociedad del Conocimiento", mientras que la categoría "regular" aumenta su representación porcentual hasta casi un $62 \%$. Desde este punto de vista, los datos recabados en relación al factor "Currículum" revelan que los establecimientos educativos donde se desempeñan los docentes encuestados estarían con dificultades para asegurar una buena implementación de la Reforma basada en competencias. Sin embargo, los porcentajes observados en la categoría "inadecuada" no varían significativamente, manteniéndose en el 2,3\%, es decir, por debajo del 4,6\% de respuestas que alcanza la escala general de implementación. 
Gráfico n. ${ }^{\circ}$ 4.3. Factor Currículum.

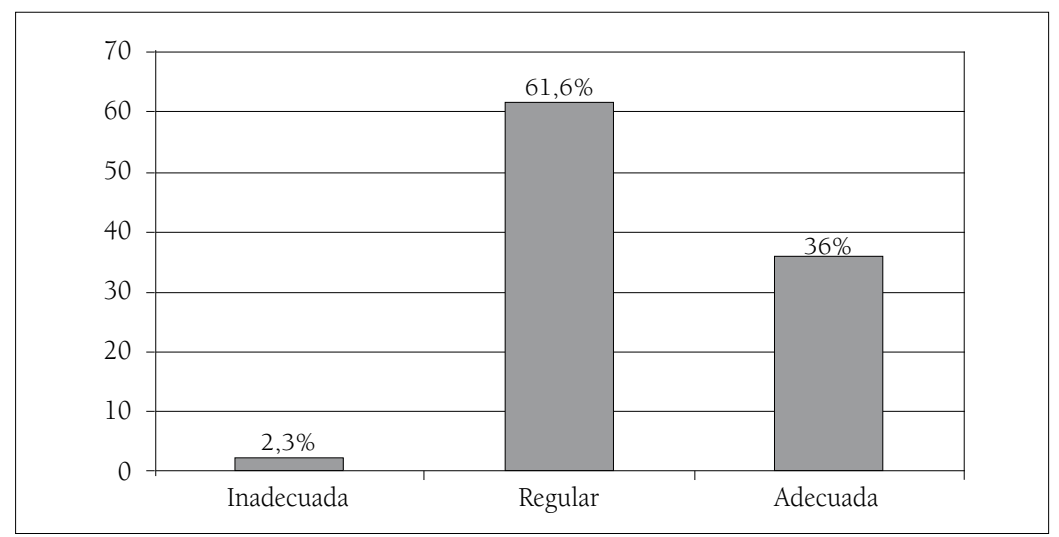

A continuación se entregan las representaciones porcentuales del factor "Institución Educativa". Dicho de otra forma, se observa el desempeño de liceos de enseñanza técnico-profesional desde la capacidad que tiene la propia institución para generar y asegurar mecanismos que le otorguen soporte a la implementación de la Reforma de la EMTP.

Lo más relevante que se consigna en el gráfico n. ${ }^{\circ} 4.4$ tiene relación con el incremento significativo que experimenta la representación porcentual de los docentes que se identifican con la categoría "inadecuada". Si en el caso del factor "Currículum" el porcentaje se mantenía en un 2,3\%, para el caso del factor "Institución Educativa" sobrepasaba el 30\%. Esto quiere decir que prácticamente un tercio del total de los docentes encuestados indican que su establecimiento tiene una baja capacidad para liderar el trabajo curricular. 
Gráfico N. ${ }^{\circ} 4.4$. Factor Institución Educativa.

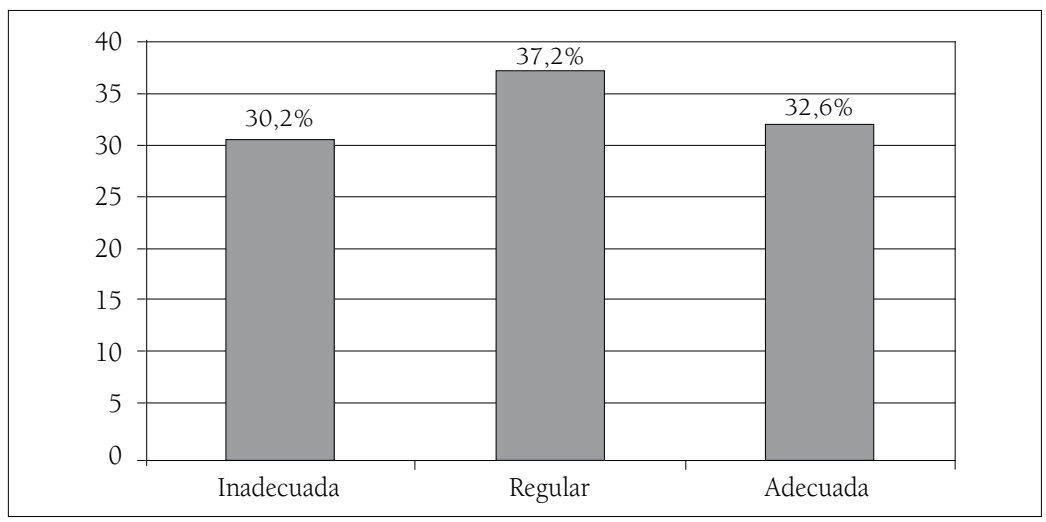

Por último, en el gráfico n. ${ }^{\circ} 4.5$ se ilustra la situación del factor "Política Educativa", donde se corrobora que los establecimientos a los que pertenecen los docentes tendrían una baja capacidad para canalizar las políticas educativas a favor de una mejor implementación de la reforma. Ello dado que un 20,9\% de los encuestados responde que es inadecuada y el 44,2\% sostiene que es apenas regular.

De esta manera, en consideración a los datos presentados en los gráficos anteriores, es en los factores "Institución Educativa" y "Política Educativa" donde se registran las principales debilidades y los mayores desafíos para mejorar la implementación de la Reforma basada en competencias laborales.

Gráfico n. ${ }^{0}$ 4.5. Factor Política Educativa.

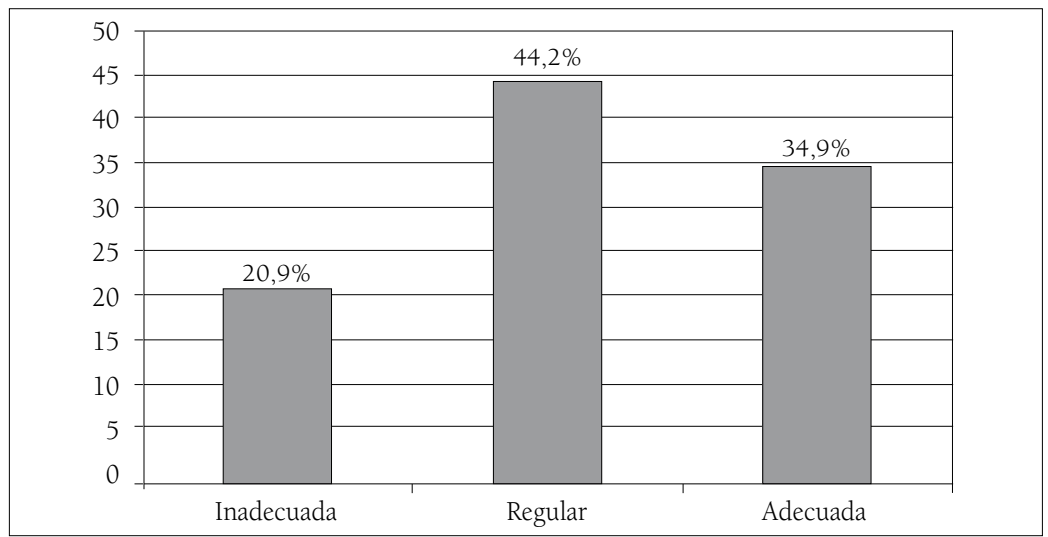




\section{Evaluación desagregada por factores y especialidad}

En las próximas tablas y gráficos se ha desagregado la información a partir del cruce de cada uno de los cuatro factores por especialidad. En el gráfico n. ${ }^{0} 4.6$ se puede comparar el porcentaje observado en la escala general según especialidad. Ahora bien, si se considera que en la especialidad de Contabilidad el porcentaje de respuestas asociables a la categoría "adecuada" llega a 31,8\% y en el caso de Electricidad para la misma categoría este porcentaje sube al $42,9 \%$, entonces es posible afirmar que desde la perspectiva de las percepciones de los docentes, en términos generales, la especialidad de Electricidad estaría implementando de mejor forma el currículum técnico profesional.

Gráfico n. ${ }^{\circ}$ 4.6. Escala general de implementación de la reforma curricular según especialidad.

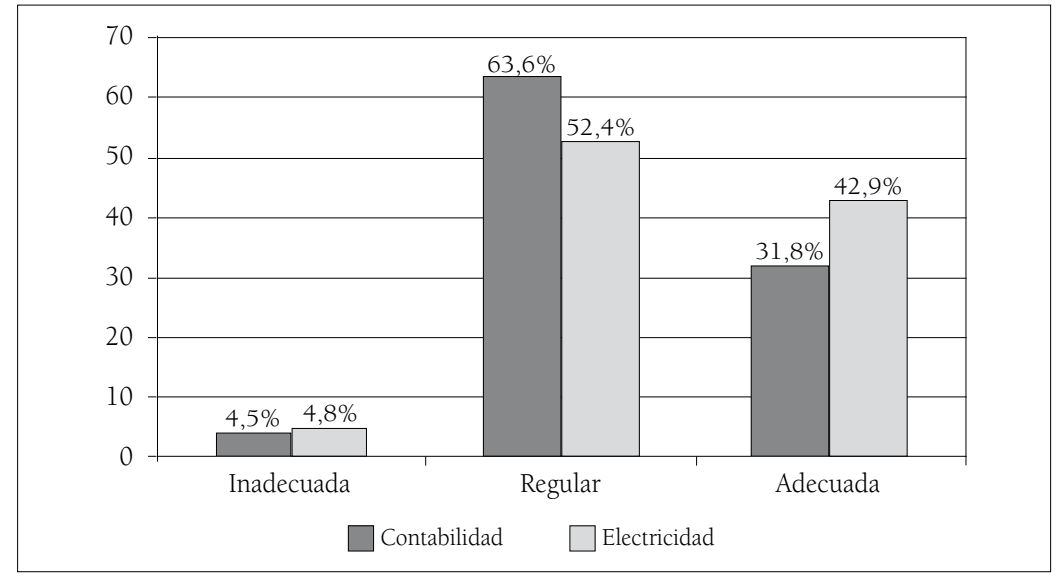

Cuando se comparan las percepciones de los docentes de las dos especialidades en función del factor "Sociedad del Conocimiento", los valores vuelven a mostrar que en la categoría "adecuada", el desempeño de la especialidad de Electricidad es mejor que el registrado por Contabilidad. No obstante, esta información tiende a relativizarse cuando se comparan los porcentajes de la categoría "inadecuada", pues en el caso de Electricidad se registra un 4,8\% de los encuestados, mientras que en Contabilidad no se registran opiniones de docentes que permitan sostener que se está implementando inadecuadamente la Reforma (tabla n. ${ }^{\circ} 4.1$ ). 
Tabla n. ${ }^{\circ}$ 4.1. Factor Sociedad del Conocimiento y Especialidad

\begin{tabular}{|l|c|c|c|}
\hline \multirow{2}{*}{ Categoría } & \multicolumn{2}{|c|}{ Especialidad } & \multirow{2}{*}{ Total } \\
\cline { 2 - 3 } & Contabilidad & Electricidad & \\
\hline Inadecuada & $0,0 \%$ & $4,8 \%$ & $2,3 \%$ \\
\hline Regular & $61,4 \%$ & $52,4 \%$ & $57,0 \%$ \\
\hline Adecuada & $38,6 \%$ & $42,9 \%$ & $40,7 \%$ \\
\hline Total & $100,0 \%$ & $100,0 \%$ & $100,0 \%$ \\
\hline
\end{tabular}

Conforme se consigna en la tabla n. ${ }^{\circ} 4.2$ para el caso del factor "Currículum" se corrobora que el desempeño de la especialidad de Electricidad, una vez más, es mejor percibido que el de la especialidad de Contabilidad por parte de los docentes. Esta constatación se sostiene en el hecho de que si bien en la categoría "inadecuada" los porcentajes de respuesta no muestran una diferencia significativa, en el caso de la categoría "regular" la tasa de respuesta es claramente favorable a Electricidad (70,5\% versus 52,4\%, respectivamente).

Tabla n. ${ }^{\circ}$ 4.2. Factor Currículum y Especialidad

\begin{tabular}{|l|c|c|c|}
\hline \multirow{2}{*}{ Categoría } & \multicolumn{2}{|c|}{ Especialidad } & \multirow{2}{*}{ Total } \\
\cline { 2 - 3 } & Contabilidad & Electricidad & \\
\hline Inadecuada & $2,3 \%$ & $2,4 \%$ & $2,3 \%$ \\
\hline Regular & $70,5 \%$ & $52,4 \%$ & $61,6 \%$ \\
\hline Adecuada & $27,3 \%$ & $45,2 \%$ & $36,0 \%$ \\
\hline Total & $100,0 \%$ & $100,0 \%$ & $100,0 \%$ \\
\hline
\end{tabular}

Lo más relevante de la comparación de los porcentajes al interior del factor "Institución Educativa" se relaciona con el hecho de que ambas especialidades tienen una importante proporción de docentes encuestados que señalan que en sus establecimientos existen evidencias de una "inadecuada" implementación curricular. Sin perjuicio de lo anterior, el porcentaje de respuestas registrado en la especialidad de Contabilidad llega al 40,9\%, mientras que en el caso de Electricidad asciende al 19\%. Es decir, en consideración a las percepciones que tienen los docentes de Contabilidad, es posible señalar que en esta especialidad el alto porcentaje de la categoría "inadecuada" del factor "Institución Educativa" denota que en los establecimientos educativos donde se imparte dicha especialidad no se estarían dando las condiciones necesarias para implementar el currículum técnico-profesional (ver tabla n. ${ }^{\circ} 4.3$ ). 
Tabla n. ${ }^{\circ}$ 4.3. Factor Institución Educativa y Especialidad

\begin{tabular}{|l|c|c|c|}
\hline \multirow{2}{*}{ Categoría } & \multicolumn{2}{|c|}{ Especialidad } & \multirow{2}{*}{ Total } \\
\cline { 2 - 3 } & Contabilidad & Electricidad & \\
\hline Inadecuada & $40,9 \%$ & $19,0 \%$ & $30,2 \%$ \\
\hline Regular & $36,4 \%$ & $38,1 \%$ & $37,2 \%$ \\
\hline Adecuada & $22,7 \%$ & $42,9 \%$ & $32,6 \%$ \\
\hline Total & $100,0 \%$ & $100,0 \%$ & $100,0 \%$ \\
\hline
\end{tabular}

Una situación relativamente similar se advierte en el factor "Política Educativa", pues aun cuando los porcentajes de la categoría "inadecuada" disminuyen respecto del factor "Institución Educativa", las tendencias al interior y entre las dos especialidades no cambian radicalmente (ver tabla n. ${ }^{\circ} 4.4$ ).

Tabla n. ${ }^{\circ}$ 4.4. Factor Política Educativa y Especialidad

\begin{tabular}{|l|c|c|c|}
\hline \multirow{2}{*}{ Categoría } & \multicolumn{2}{|c|}{ Especialidad } & \multirow{2}{*}{ Total } \\
\cline { 2 - 3 } & Contabilidad & Electricidad & \\
\hline Inadecuada & $25,0 \%$ & $16,7 \%$ & $20,9 \%$ \\
\hline Regular & $43,2 \%$ & $45,2 \%$ & $44,2 \%$ \\
\hline Adecuada & $31,8 \%$ & $38,1 \%$ & $34,9 \%$ \\
\hline Total & $100,0 \%$ & $100,0 \%$ & $100,0 \%$ \\
\hline
\end{tabular}

El gráfico n. ${ }^{\circ} 4.7$ resume el desempeño de las dos especialidades cuando se comparan los porcentajes obtenidos en la categoría "adecuada" implementación de la Reforma curricular. Es así como en los cuatro factores la especialidad de Contabilidad muestra un proceso de implementación más modesto que el observado en la especialidad de Electricidad, situación que queda de manifiesto en el factor "Institución Educativa", mientras que en el caso del factor "Sociedad del Conocimiento" las diferencias son más estrechas. Con todo, es posible sostener que desde la perspectiva de los docentes, la especialidad de Contabilidad tiene más dificultades en los cuatro factores en los que se ha evaluado la implementación de la Reforma curricular en la enseñanza técnico-profesional. 
Gráfico n. ${ }^{\circ}$ 4.7. Adecuada implementación curricular (\%).

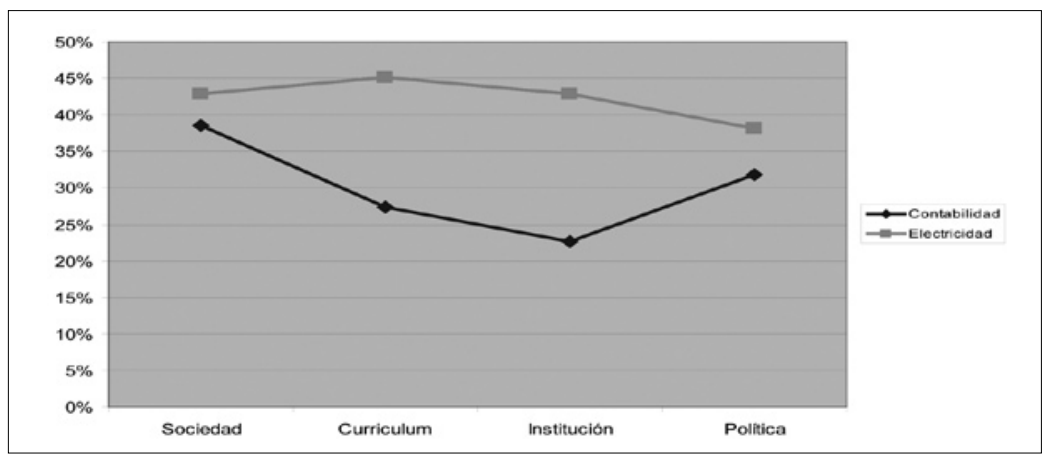

\section{Evaluación desagregada por factores y tipo de sostenedor}

En el gráfico n. 4.8 se relacionan las tres categorías de la implementación de la Reforma curricular basada en competencias laborales, según el tipo de sostenedor que administra el establecimiento educativo en el que laboran los docentes consultados mediante la encuesta. Los datos revelan que mientras los docentes de los establecimientos de administración delegada perciben que en sus liceos el currículo es implementado adecuadamente $(63,2 \%)$, los de las instituciones municipales indican que en sus unidades educativas la Reforma es conducida en forma regular $(77,8 \%)$.

Gráfico n. ${ }^{\circ}$ 4.8. Implementación de la reforma curricular y tipo de sostenedor.

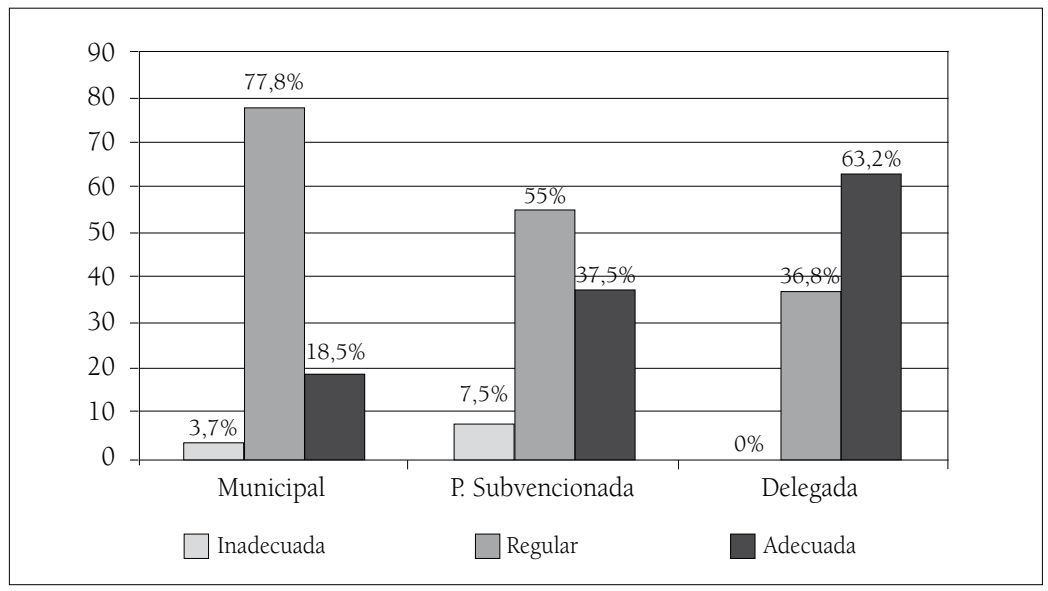


En la tabla n. ${ }^{\circ} 4.5$, por otra parte, se da cuenta de la percepción que tienen los docentes del desempeño de sus respectivos establecimientos escolares, cuando se compara el factor "Sociedad del Conocimiento" y el tipo de sostenedor administrativo. Según estos datos, los liceos de administración delegada obtienen un mejor resultado, pero también es interesante constatar que los docentes de liceos de administración municipal no consideran que la implementación de la reforma curricular sea inadecuada, mientras que en las instituciones particulares subvencionadas y de administración delegada un 2,5\% y 5,3\%, respectivamente, estiman que en sus instituciones la implementación sería inadecuada. Sin perjuicio de lo anterior, los docentes de estas últimas instituciones educativas opinan que este tipo de sostenedor es el que tiene mejor desempeño en el tratamiento de variables que emanan de la sociedad del conocimiento para implementar exitosamente el currículum en la modalidad técnico-profesional.

Tabla n. ${ }^{\circ}$ 4.5. Factor Sociedad del Conocimiento y tipo de sostenedor

\begin{tabular}{|l|c|c|c|c|}
\hline \multirow{2}{*}{ Categoría } & \multicolumn{3}{|c|}{ Tipo de Sostenedor } & \multirow{2}{*}{ Total } \\
\cline { 2 - 4 } & Municipal & $\begin{array}{c}\text { Particular } \\
\text { subvencionado }\end{array}$ & $\begin{array}{c}\text { Administración } \\
\text { delegada }\end{array}$ & \\
\hline Inadecuada & $0,0 \%$ & $2,5 \%$ & $5,3 \%$ & $2,3 \%$ \\
\hline Regular & $63,0 \%$ & $60,0 \%$ & $42,1 \%$ & $57,0 \%$ \\
\hline Adecuada & $37,0 \%$ & $37,5 \%$ & $52,6 \%$ & $40,7 \%$ \\
\hline Total & $100,0 \%$ & $100,0 \%$ & $100,0 \%$ & $100,0 \%$ \\
\hline
\end{tabular}

A su turno, cuando se considera el factor "Currículum", los liceos de administración delegada vuelven a confirmar su buen desempeño. De hecho, prácticamente un 73,7\% del total de docentes encuestados vinculados a ese tipo de establecimientos estima que en su unidad se trabajan adecuadamente las variables asociadas al factor "Currículum". Una tendencia que contrasta con la situación que se aprecia en las instituciones particulares subvencionadas y especialmente en los liceos municipalizados. En efecto, un 30\% de los docentes que laboran en instituciones particulares subvencionadas estima que la Reforma en EMTP se estaría implementando adecuadamente y sólo un 18,5\% de los profesores municipalizados perciben que en estos liceos se están incorporando adecuadamente las variables del factor "Currículum" (ver tabla n. ${ }^{\circ} 4.6$ ). 
132 EVALUACIÓN DE LA REFORMA CURRICULAR EN EDUCACIÓN MEDIA TÉCNICOPROFESIONAL - Óscar Espinoza, Dante Castillo, Patricio Traslaviña

Tabla n. ${ }^{\circ}$ 4.6. Factor Currículum y tipo de sostenedor

\begin{tabular}{|l|c|c|c|c|}
\hline \multirow{2}{*}{ Categoría } & \multicolumn{3}{|c|}{ Tipo de Sostenedor } & \multirow{2}{*}{ Total } \\
\cline { 2 - 4 } & Municipal & $\begin{array}{c}\text { Particular } \\
\text { subvencionado }\end{array}$ & $\begin{array}{c}\text { Administración } \\
\text { delegada }\end{array}$ & \\
\hline Inadecuada & $3,7 \%$ & $2,5 \%$ & $0,0 \%$ & $2,3 \%$ \\
\hline Regular & $77,8 \%$ & $67,5 \%$ & $26,3 \%$ & $61,6 \%$ \\
\hline Adecuada & $18,5 \%$ & $30,0 \%$ & $73,7 \%$ & $36,0 \%$ \\
\hline Total & $100,0 \%$ & $100,0 \%$ & $100,0 \%$ & $100,0 \%$ \\
\hline
\end{tabular}

El panorama que muestra el factor "Institución Educativa" evidencia una fuerte caída en los desempeños de los establecimientos particulares subvencionados y aún con mayor fuerza en los de administración municipalizada. En efecto, a partir de las declaraciones realizadas por los docentes que laboran en liceos particulares subvencionados, se constata que un $32,5 \%$ de ellos percibe que sus instituciones estarían implementando inadecuadamente la Reforma de la enseñanza técnico-profesional, en la medida que no se estarían abordando eficientemente las variables vinculadas al factor "Institución Educativa”. En los liceos municipalizados, asimismo, un 48,1\% del total de docentes encuestados suministran información que permite conocer su percepción respecto a la implementación de la Reforma en lo que se refiere a las variables del Factor "Institución Educativa". Por el contrario, los datos confirman el buen desempeño de las instituciones de administración delegada, a partir de las evidencias que se extraen de las declaraciones realizadas por los docentes de este tipo de liceos. Es así como un 63,2\% de los docentes de liceos de administración delegada piensa que su institución estaría implementando adecuadamente la Reforma de un currículum basado en competencias, considerando las variables asociadas al factor "Institución Educativa" (ver tabla n. ${ }^{\circ} 4.7$ ).

Tabla n. ${ }^{\circ}$ 4.7. Factor Institución Educativa y tipo de sostenedor.

\begin{tabular}{|l|c|c|c|c|}
\hline \multirow{2}{*}{ Categoría } & \multicolumn{3}{|c|}{ Tipo de Sostenedor } & \multirow{2}{*}{ Total } \\
\cline { 2 - 4 } & Municipal & $\begin{array}{c}\text { Particular } \\
\text { subvencionado }\end{array}$ & $\begin{array}{c}\text { Administración } \\
\text { delegada }\end{array}$ & \\
\hline Inadecuada & $48,1 \%$ & $32,5 \%$ & $0,0 \%$ & $30,2 \%$ \\
\hline Regular & $44,4 \%$ & $32,5 \%$ & $36,8 \%$ & $37,2 \%$ \\
\hline Adecuada & $7,4 \%$ & $35,0 \%$ & $63,2 \%$ & $32,6 \%$ \\
\hline Total & $100,0 \%$ & $100,0 \%$ & $100,0 \%$ & $100,0 \%$ \\
\hline
\end{tabular}


Respecto de las variables asociables al factor "Política Educativa", los antecedentes vuelven a confirmar la tendencia observada en los liceos de administración delegada. Pero es interesante destacar que, en términos comparativos, un $27,5 \%$ del total de docentes que trabaja en colegios particulares subvencionados perciben que en sus establecimientos no se estaría implementando adecuadamente el currículum TP, en la medida que no se estarían abordando correctamente las variables del factor "Política Educativa" (ver tabla n. $\left.{ }^{\circ} 4.8\right)$.

Tabla n. ${ }^{\circ}$ 4.8. Factor política educativa y tipo de sostenedor.

\begin{tabular}{|l|c|c|c|c|}
\hline \multirow{2}{*}{ Categoría } & \multicolumn{3}{|c|}{ Tipo de Sostenedor } & \multirow{2}{*}{ Total } \\
\cline { 2 - 4 } & Municipal & $\begin{array}{c}\text { Particular } \\
\text { subvencionado }\end{array}$ & $\begin{array}{c}\text { Administración } \\
\text { delegada }\end{array}$ & \\
\hline Inadecuada & $18,5 \%$ & $27,5 \%$ & $10,5 \%$ & $20,9 \%$ \\
\hline Regular & $63,0 \%$ & $42,5 \%$ & $21,1 \%$ & $44,2 \%$ \\
\hline Adecuada & $18,5 \%$ & $30,0 \%$ & $68,4 \%$ & $34,9 \%$ \\
\hline Total & $100,0 \%$ & $100,0 \%$ & $100,0 \%$ & $100,0 \%$ \\
\hline
\end{tabular}

\section{Evaluación de la reforma a partir del análisis de los vectores}

Tal como se ha señalado anteriormente, en función de la revisión documental y específicamente sobre la base de la descripción de los perfiles de egreso de las cuarenta y seis especialidades que imparte actualmente la enseñanza media técnico-profesional, se construyó el modelo de vectores que permitió determinar los efectos de la reforma curricular en los establecimientos sobre la base de las percepciones de los docentes. Los vectores se asocian a grupos de capacidades según las características del trabajo específico de cada especialidad, y pueden dimensionarse en diferentes niveles o intensidades. En el modelo elaborado se han identificado ocho vectores comunes a todas las especialidades del actual currículo nacional (ver figura n..$^{\circ} 2.1$ ), graduados a su vez en una escala que va de uno a seis puntos. Es decir, cada vector puede variar su puntuación en función de las características de la especialidad que se esté analizando.

El análisis de los perfiles de egreso de las dos especialidades abordadas permite obtener un modelo de vectores ideal para cada 
una de ellas. Sobre esa base y a partir de los datos que proporciona el trabajo de campo, es posible contrastar el modelo ideal con el empírico que surge de la observación realizada en los establecimientos educacionales.

De la comparación entre el modelo teórico y empírico de cada especialidad, y las diferencias entre los esquemas de Electricidad y Contabilidad, se determinó la pertinencia de este modelo de vectores como instrumento válido para abordar los efectos de la reforma curricular en la EMTP.

Los resultados que se presentan a continuación dan cuenta del tipo de capacidades que los docentes definen como indispensables para las especialidades estudiadas de modo que los egresados tengan las capacidades necesarias para hacer frente adecuadamente a las exigencias que les demanda el mundo laboral.

\section{Resultados de la evaluación a partir de la aplicación del Modelo de Vectores}

En este apartado se da cuenta de los resultados que se obtienen a partir de las percepciones de los docentes encuestados de las dos especialidades sometidas a análisis mediante la aplicación del modelo de vectores elaborado por los autores.

En el gráfico n. ${ }^{\circ} 5.1$ se detalla la distribución de respuestas que han entregado los docentes, a partir de la importancia o pertinencia que se le otorga a cada vector. En este primer caso, el nivel 1 indica que el trabajo desarrollado por los egresados de la especialidad es realizado en un ambiente cerrado con actividad física mínima y las variables ambientales están controladas. Mientras que en el extremo opuesto de la escala, señalado con el nivel 6, se identifica al trabajo que es realizado permanentemente al aire libre, donde existen riesgos físicos porque las variables ambientales son extremas y no están controladas.

En virtud de la información proporcionada por los docentes de las dos especialidades se puede apreciar que para el caso aquellos que 
se desempeñan en la especialidad de Contabilidad éstos concentran sus respuestas en los niveles más bajos, lo que implica que esta especialidad se caracteriza por desenvolverse en ambientes cerrados y controlados con baja actividad física, situación inversa a la de Electricidad (ver gráfico n. ${ }^{\circ}$ 5.1).

Gráfico n. ${ }^{\circ}$ 5.1. Especialidad y vector 1: entorno laboral.

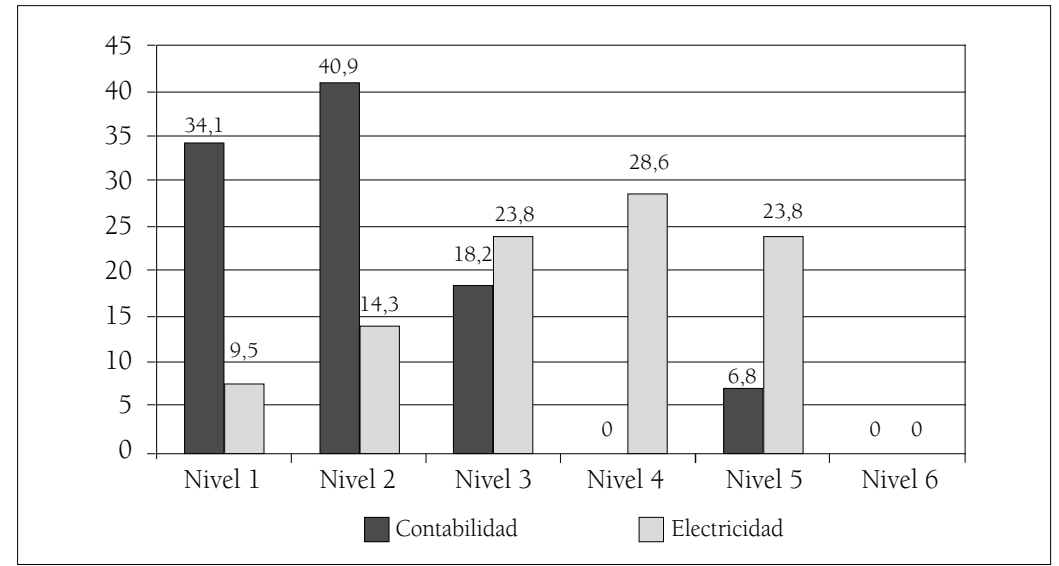

Con el segundo vector se da cuenta del manejo de documentación normativa y legal que puede asociarse a las especialidades. De esta forma, el nivel 1 indica que la especialidad, desde la perspectiva del docente, maneja una pequeña cantidad de documentos de carácter básico, mientras que en el extremo opuesto, el nivel 6 señala que la especialidad maneja una gran cantidad de información de carácter confidencial para fines legales y/o comerciales. Ahora bien, según los datos obtenidos a partir de las declaraciones de los docentes, la especialidad de Electricidad tiende a concentrar las opiniones en los niveles medios y bajos, mientras que en el caso de Contabilidad una proporción importante de docentes clasifica a este vector en los puntos medios y altos (ver gráfico n. ${ }^{0}$ 5.2). 
Gráfico n. ${ }^{\circ}$ 5.2. Especialidad y vector 2. Manejo de documentación normativa y legal.

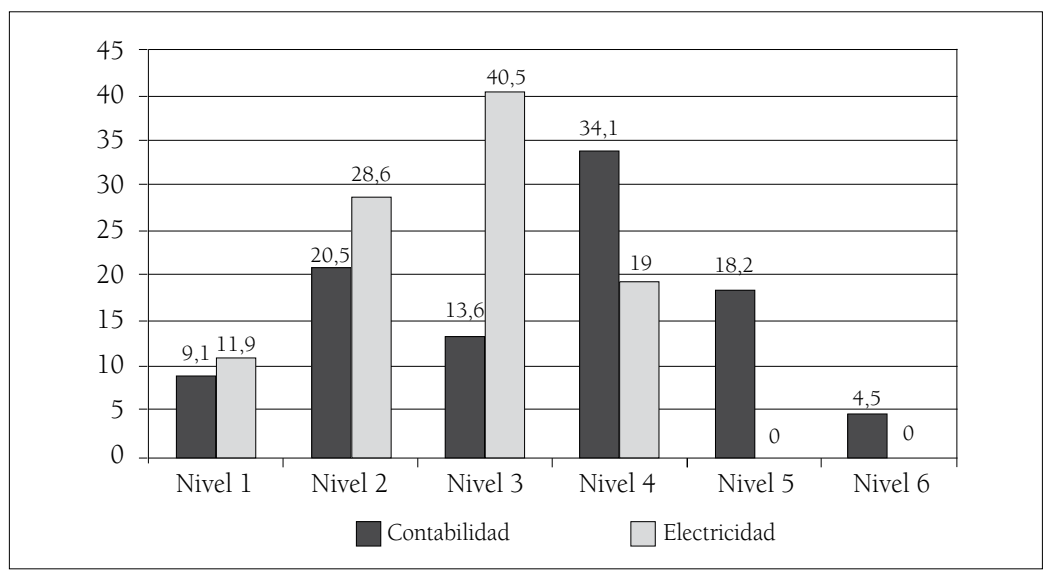

A su vez, el nivel 1 del tercer vector señala a una especialidad que desde el punto de vista del manejo de habilidades cognitivas, busca y lee información y/o documentación con la que debe llevar a cabo actividades básicas de la especialidad. En el otro extremo, el nivel 6 alude a una especialidad donde se formulan hipótesis, indagando diferentes respuestas y se elaboran soluciones alternativas con fundamento para resolver problemas.

La evaluación de las percepciones de los docentes encuestados permite constatar que existirían diferencias entre la especialidad de Contabilidad y Electricidad. De hecho, en el gráfico n. ${ }^{\circ} 5.3$ es posible observar una tendencia inversamente proporcional. Es decir, mientras la especialidad de Contabilidad registra una concentración de las opiniones en los niveles de manejo de habilidades cognitivas más altos, la especialidad de Electricidad se concentra en los niveles bajos. 
Gráfico n. ${ }^{\circ}$ 5.3. Vector 3: Manejo de habilidades cognitivas y especialidad.

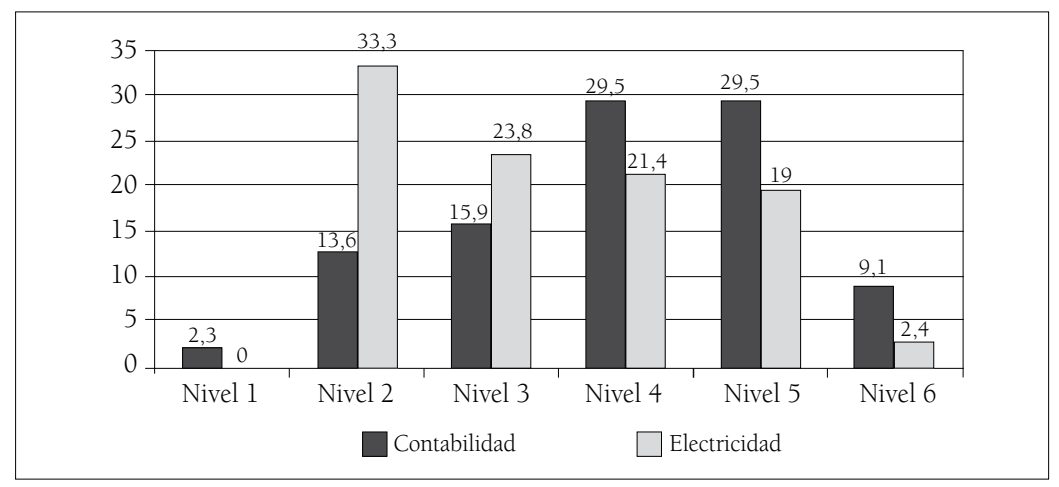

Con el vector 4 se buscó graduar la operación y uso de equipamiento tecnológico. De esta manera, la escala comienza en el nivel 1 , que denota a una especialidad que utiliza equipamiento tecnológico básico y de características generales. En el extremo opuesto de la escala el nivel 6 alude a una especialidad donde se establecen diagnósticos fundados y se planifican procedimientos para la realización de acciones de mantenimiento de máquinas, equipos, instalaciones y sistemas.

Tal como se aprecia en el gráfico n. ${ }^{\circ}$ 5.4, los resultados comparativos entre ambas especialidades indican que los docentes de la especialidad de Contabilidad reconocen una baja operación y uso de equipamiento tecnológico (sobre el $80 \%$ de las respuestas se concentra en los niveles 1 y 2), mientras que en el caso de la especialidad de Electricidad un porcentaje importante de docentes clasificó a esta especialidad en los niveles 4, 5 y 6, es decir, con mayor operación y uso de equipamiento tecnológico. 
Gráfico n. ${ }^{0}$ 5.4. Vector 4: Operación y uso de equipamiento tecnológico y especialidad.

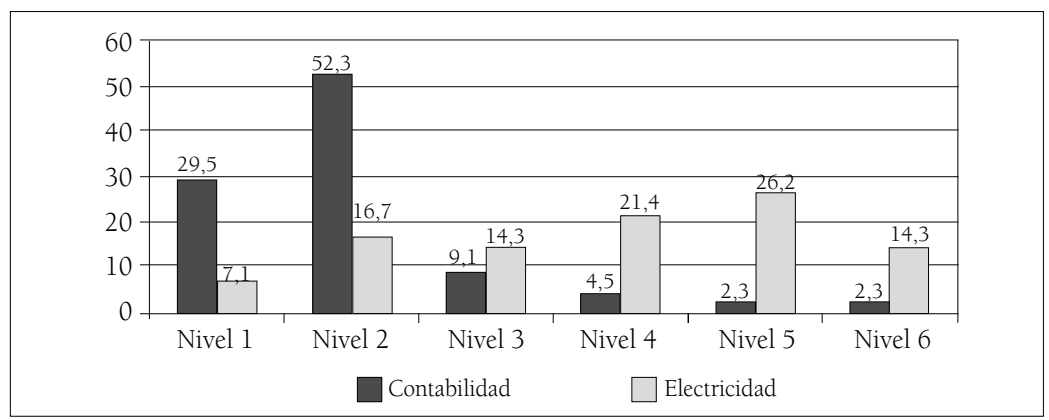

El nivel 1 del vector 5, Cooperación y Comunicación, da cuenta de una especialidad donde los egresados trabajan en forma individual, mientras que los procesos de comunicación con pares, superiores y otros funcionarios de la institución son espontáneos. En cambio, el nivel 6 significa que en la especialidad se comprende, analiza y se generan mejoras en la calidad del sistema de comunicaciones formales e informales de la organización donde se desempeñan los egresados.

Los resultados obtenidos de las encuestas de percepción aplicadas a los docentes muestran que las diferencias entre ambas especialidades serían menos categóricas que en los vectores descritos anteriormente, situación que evidencia que con relación al vector 5 , los egresados de Contabilidad y Electricidad desarrollarían capacidades similares (ver gráfico n. ${ }^{\circ}$ 5.5).

Gráfico n. ${ }^{\circ}$ 5.5. Vector 5: Cooperación y comunicación y especialidad.

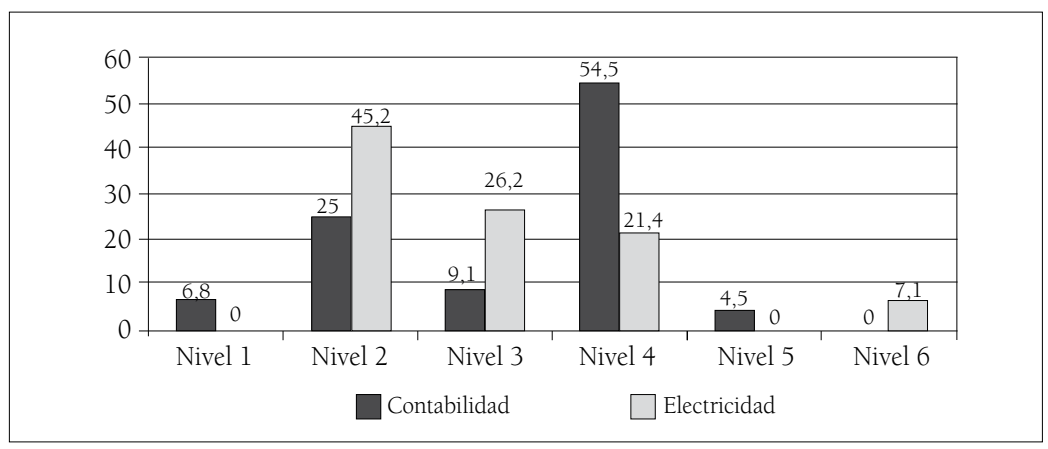


En el vector 6, "Manejo de información gráfica y simbólica", el nivel 1 significa que los egresados de la especialidad se desenvuelven en un ambiente laboral donde se interpreta información icónica de carácter básico, en tanto que en el otro extremo de la escala, el nivel 6 da cuenta que en el ambiente laboral de egresados de la especialidad se elaboran e interpretan planos de complejidad mediana de acuerdo a normas y legislación vigente.

Al sistematizar la información proporcionada por los docentes consultados de ambas especialidades, se verifica que en Contabilidad sus declaraciones se concentran en los niveles inferiores (76\% entre los niveles 2 y 4), mientras que desde la perspectiva de los docentes de Electricidad, los egresados de ella necesitarían capacidades para desempeñarse en los niveles más altos de este vector (66\% entre los niveles 4 y 6), es decir, con mayor manejo de información gráfica y simbólica (gráfico n. ${ }^{\circ}$ 5.6).

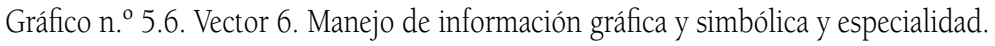

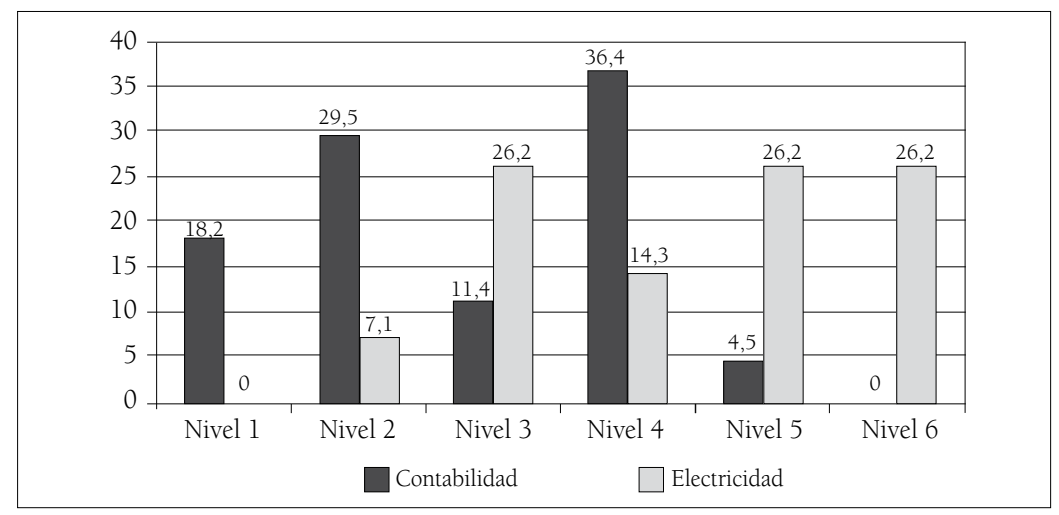

El vector 7 está referido a las capacidades de trabajo corporal y habilidades específicas que caracterizan a las especialidades. En este caso, el nivel 1 asociado a dicho vector alude a una especialidad donde no se requiere esfuerzo físico significativo, ni de habilidades específicas de ningún tipo, mientras que el nivel 6 de la escala caracteriza a una especialidad donde se requiere de gran esfuerzo físico y en forma constante porque las condiciones de trabajo son siempre adversas, por lo que se requiere constante entrenamiento de la condición física. 
A partir de los datos recabados en las encuestas realizadas a los docentes, se verifica que la especialidad de Electricidad es la que tendría mayor intensidad en la actividad física. De hecho, mientras Contabilidad registra un 2,3\% en el nivel 5 (más intensidad), la especialidad de Electricidad registra un 19\%. Diferencia que se mantiene en el nivel 4 (ver gráfico n. ${ }^{\circ}$ 5.7).

Por último, con el vector 8 se establece el nivel de seguridad y prevención de riesgos, entendiendo que el nivel 1 está referido a una especialidad donde se trabaja en condiciones completamente controladas y no existe ningún peligro de accidente. Por el contrario, en el nivel 6 de esta escala se alude a una especialidad donde los egresados trabajan en condiciones adversas y existe riesgo permanente de accidentes porque se trabaja con herramientas y/o materiales muy peligrosos.

Gráfico n. ${ }^{0}$ 5.7. Vector 7: Trabajo corporal y habilidades específicas y especialidad.

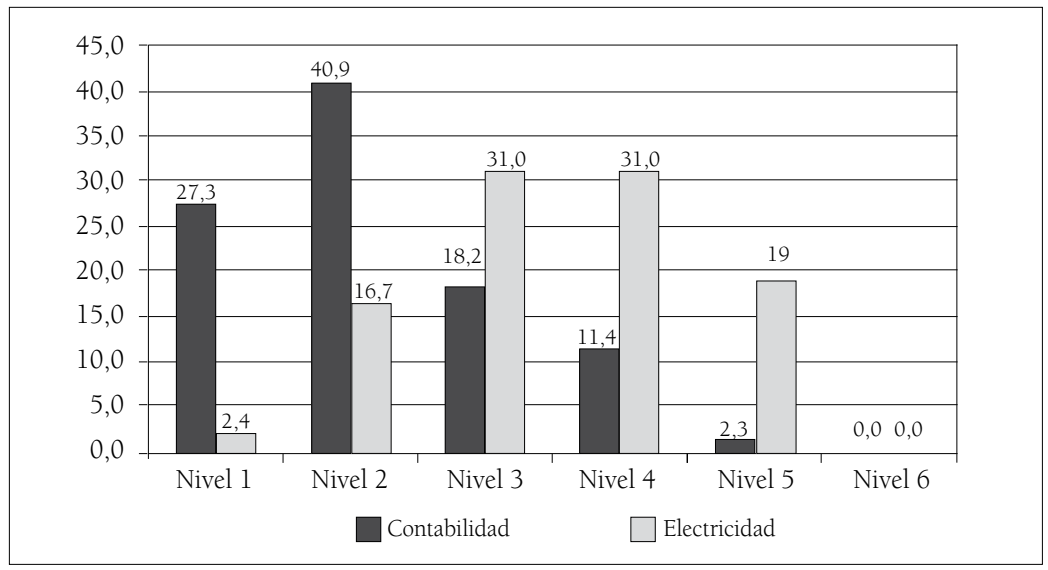

Considerando las respuestas proporcionadas por los encuestados, se advierte que los docentes de la especialidad de Contabilidad perciben que los egresados se desempeñan o desempeñarán en ambientes laborales de bajo riesgo. En contraste, en la especialidad de Electricidad, la opinión siendo heterogénea entre los encuestados tiende a concentrase en los niveles medios y altos en el reconocimiento de condiciones de trabajo riesgosas (ver gráfico n. ${ }^{\circ}$ 5.8). 
Gráfico n. ${ }^{\circ}$ 5.8. Vector 8. Seguridad y Prevención de Riesgos y Especialidad.

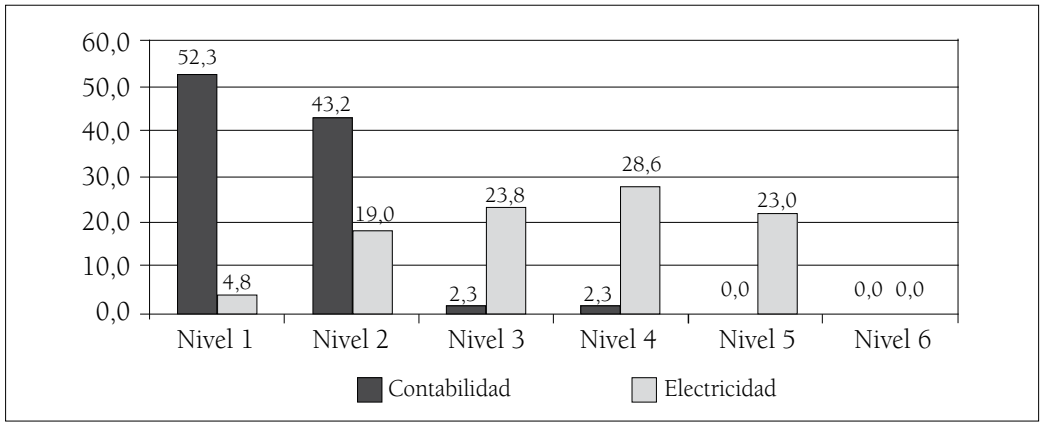

\section{Comparaciones entre el modelo teórico y empírico de vectores}

Si con la información que han proporcionado las tablas y gráficos anteriores fue posible reconstruir empíricamente las tendencias de cada especialidad, a partir del nivel en que los docentes sitúan a cada vector, con los datos que se presentan a continuación se busca establecer la convergencia entre el nivel teórico y el práctico. Es decir, se busca determinar la coherencia entre un nivel teórico en el que se encuentra cada vector de una especialidad considerando los perfiles de egreso reconocidos y sancionados por la reforma de la EMTP y el valor promedio de las evaluaciones realizadas por los docentes encuestados.

Para realizar esta comparación se procedió de dos formas. En primer lugar, se estimó el valor ideal que registra cada vector, al extraer y ponderar las definiciones y orientaciones conceptuales que se enuncian en las funciones y tareas identificadas en los perfiles profesionales y en las capacidades del perfil de egreso de las especialidades. ${ }^{2}$ En este caso se analizó la documentación de las especialidades de Electricidad y Contabilidad. De esta manera, se asignó un nivel teórico o ideal para cada uno de los ocho vectores. Por ejemplo, para Electricidad, el vector 6 (manejo de información

2 Consultar Perfiles de Egreso (Objetivos Fundamentales Terminales) de las diferentes especialidades descritas en el Decreto Ley 220 de 1998. 
gráfica y simbólica) se estimó en el nivel 6 , mientras que para este mismo vector en la especialidad de Contabilidad el nivel teórico se estimó en el nivel 2 (ver tabla 5.1).

Segundo, una vez que se estimó el valor ideal o teórico de cada vector en ambas especialidades, se procedió a determinar el valor de cada nivel para los ocho vectores de las dos especialidades tomando como referencia la percepción que tienen los docentes sobre el particular. Este procedimiento se realizó calculando el promedio o la media aritmética que se obtuvo a partir de los valores que cada docente encuestado le otorgó a los vectores. En la tabla n. ${ }^{\circ} 5.1$ se detallan los valores de los niveles teóricos, obtenidos con la información documental y los valores de los niveles percibidos por los docentes, elaborados a partir de la aplicación de un cuestionario.

Tabla n. ${ }^{\circ}$ 5.1. Vector 8. Seguridad y Prevención de Riesgos y Especialidad.

\begin{tabular}{|c|c|c|c|c|}
\hline \multirow[b]{2}{*}{ Vector } & \multicolumn{2}{|c|}{ Electricidad } & \multicolumn{2}{|c|}{ Contabilidad } \\
\hline & $\begin{array}{l}\text { Nivel del modelo } \\
\text { ideal o teórico }\end{array}$ & $\begin{array}{l}\text { Evaluación o } \\
\text { percepción de los } \\
\text { docentes }\end{array}$ & $\begin{array}{l}\text { Nivel del modelo } \\
\text { ideal o teórico }\end{array}$ & $\begin{array}{l}\text { Evaluación o } \\
\text { percepción de los } \\
\text { docentes }\end{array}$ \\
\hline 1 & 2 & 3,43 & 1 & 2,05 \\
\hline 2 & 4 & 2,67 & 6 & 3,46 \\
\hline 3 & 3 & 3,33 & 5 & 3,98 \\
\hline 4 & 4 & 3,86 & 2 & 2,05 \\
\hline 5 & 3 & 2,98 & 4 & 3,25 \\
\hline 6 & 6 & 4,38 & 2 & 2,80 \\
\hline 7 & 4 & 3,48 & 1 & 2,20 \\
\hline 8 & 3 & 3,48 & 1 & 1,55 \\
\hline
\end{tabular}

En el siguiente esquema (figura n. ${ }^{\circ}$ 5.1) se observa la situación de la especialidad de Contabilidad al momento de contrastar el modelo teórico o ideal con los resultados que se obtienen a partir de las declaraciones que realizan los docentes, a través de las respuestas que han entregado en el cuestionario autoaplicado. Aquí se esquematiza la forma que adquiere esta especialidad cuando se consideran los niveles que la bibliografía oficial le asigna a cada vector y se da cuenta de la forma que adquiere a partir de los niveles promedio obtenidos en cada vector. 
Según este contraste, la diferencia más significativa entre el modelo teórico y el observado a través de las percepciones de los docentes se ubica en el vector 2 -Manejo de documentación normativa y legal-, pues mientras el nivel teórico de este vector se ubica en el nivel 6, que conceptualmente indica que esta especialidad maneja gran cantidad de documentación, el nivel del vector obtenido empíricamente (desde la percepción de los docentes) es levemente superior al nivel 3, que conceptualmente indica que la especialidad sólo registra y archiva información y documentación para distintos usos de acuerdo a pautas establecidas. Dicho de otra forma, los docentes perciben que la especialidad de Contabilidad maneja menos documentación normativa y legal que lo descrito en las orientaciones de la documentación oficial.

Figura n. ${ }^{0}$ 5.1. Especialidad de Contabilidad.

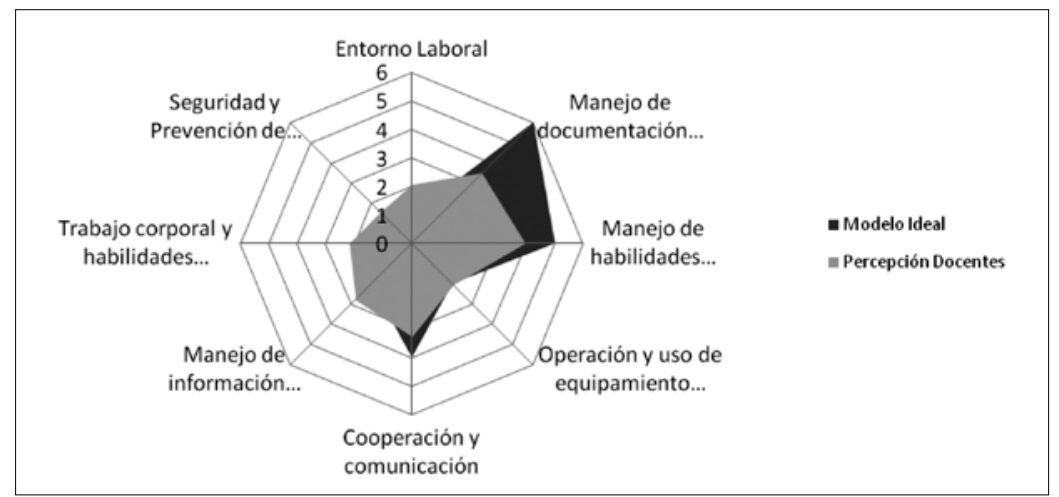

En el caso de la especialidad de Electricidad (figura n. ${ }^{\circ}$ 5.2), la diferencia más significativa se observó en el vector 6 , asociado al manejo de información gráfica y simbólica. En este caso, el nivel del modelo teórico señala que este vector debiera ubicarse en el nivel 6 que significa que en la especialidad se elaboran e interpretan planos de complejidad mediana de acuerdo a normas y legislación vigente. Empero, el valor promedio obtenido a partir de declaraciones de los docentes de esta especialidad sobrepasa levemente el nivel 4, es decir, que en ella sólo se elaboran diagramas con información de mediana complejidad. 
Figura n. ${ }^{\circ}$ 5.2. Especialidad de Electricidad.

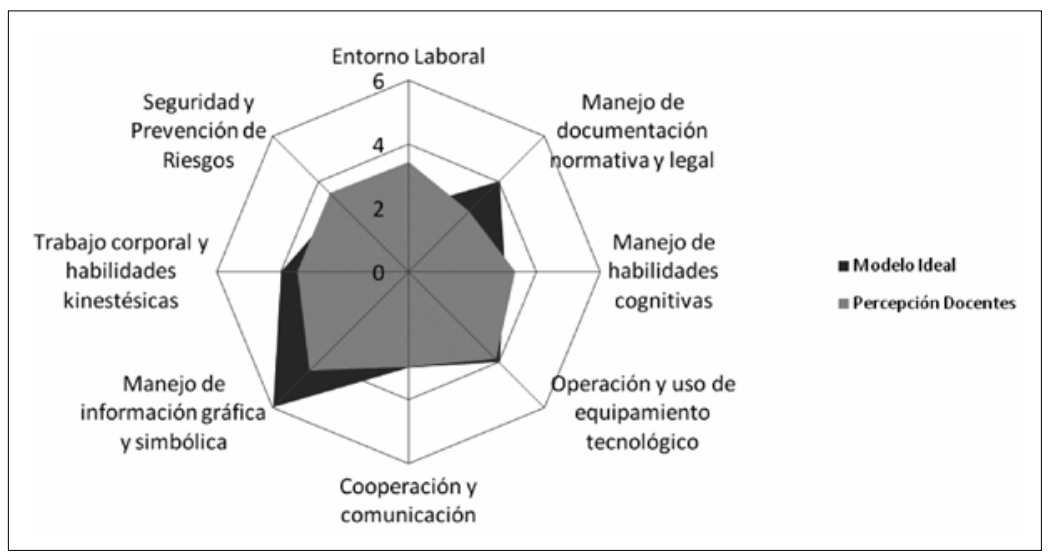

En síntesis, tal como se ha especificado anteriormente, del contraste entre valores teóricos y los asignados por los docentes es posible estimar la coherencia entre las orientaciones definidas en el Decreto 220 y la percepción que tienen los docentes, la que a su vez está directamente relacionada con la forma en que se está implementando la reforma curricular. Paralelamente, también es posible utilizar este modelo para decidir qué vectores se quisieran estimular para ajustarlos al modelo teórico o bien para decidir cuál grupo de capacidades se quisiera sobreestimular para crear perfiles de egreso con identidad diferente a la promovida por el modelo institucional sustentado en la reforma de 1998.

\section{Reflexiones finales}

Evaluar la implementación de la reforma curricular de la EMTP a partir de la percepción de los docentes, ya es un desafío de gran envergadura si se considera la complejidad que significa incluir las cuarenta y seis especialidades de la modalidad. Dicha tarea se vuelve aún más complicada cuando se requiere dar cuenta de un currículo basado en competencias laborales. Pues precisamente cuando la reforma de la EMTP el año 1998 propone la implementación de este currículum, también está reconociéndose la dificultad para centrar los aprendizajes en el contenido del éste. 
En ese contexto, el presente artículo da cuenta de una evaluación parcial de la reforma en la EMTP, cuya principal característica se relaciona con la implementación de un currículum basado en competencias laborales. Para tal efecto se evaluaron las percepciones de docentes de dos de las cuarenta y seis especialidades de la modalidad técnico-profesional por su representatividad, cobertura y heterogeneidad, a saber: Contabilidad y Electricidad.

La evaluación tuvo como pilares fundamentales dos modelos de análisis generados para este propósito: uno de factores y otro de vectores. El primero, basado en una matriz de indicadores, permitió estimar especialidades con características muy diferentes de lo que se infiere su relevancia para usarse en las restantes especialidades de la modalidad.

El modelo de vectores, por su parte, se construyó a partir de ocho grupos de capacidades presentes en las cuarenta y seis especialidades. El modelo permite ilustrar la evaluación que hacen los docentes de la reforma curricular para las especialidades abordadas en el estudio. A diferencia del modelo de factores, que puede ser aplicable en todas las especialidades, el modelo de vectores define capacidades comunes para todas las especialidades pero las intensidades o niveles de cada uno deben ser definidos para cada especialidad si es que se quiere replicar el modelo. En este estudio solo se definieron intensidades teóricas para los ocho vectores en las especialidades de Contabilidad y Electricidad.

A diferencia de lo que acontece con los modelos de evaluación curricular tradicional donde las evidencias son capturadas a partir del desempeño de los estudiantes, en el caso del modelo de factores y vectores, diseñado para evaluar la reforma de la EMTP, las evidencias son proporcionadas por directivos y docentes del sector.

Otro aspecto que establece el estudio y que buscó mostrar este artículo se relaciona con la pertinencia y validez empírica del modelo de factores para evaluar la implementación de la reforma. Es decir, si bien los factores (y los indicadores que dan cuenta de ellos) fueron elaborados en función de la revisión bibliográfica y documental, el 
contraste con las evidencias que arrojaron las encuestas dirigidas a docentes y directivos permitió avanzar en la validación del modelo teórico al menos desde la perspectiva de estos estamentos.

De esta manera, al aplicar ambos modelos los resultados permitieron evaluar la implementación del currículum basado en competencias en dieciséis establecimientos de las especialidades de Contabilidad y Electricidad. Las evidencias muestran que en el caso de Electricidad el currículum se realizaría de una forma más efectiva que en la especialidad de Contabilidad tomando como base las percepciones de los docentes.

Por otra parte, también se constató que al desagregar la información por el tipo de sostenedor, los establecimientos de administración delegada se desempeñan de manera más ajustada a la reforma basada en competencias laborales que los particulares subvencionados y municipalizados. Del mismo modo, en términos regionales, los establecimientos de la Quinta y Octava Región evidencian una mejor performance que los de la Región Metropolitana.

Cabe destacar y reiterar que tanto el modelo de factores como el de vectores son replicables al resto de las especialidades de la educación técnico-profesional, lo que los transforma en un valioso instrumento para futuras investigaciones sobre la reforma.

Por último, el presente artículo da cuenta de una evaluación parcial de la reforma en la EMTP impulsada el año 1998, en que conviene remarcar que los modelos de evaluación utilizados en el estudio que sirvió de base para este artículo no invalidan la pertinencia de realizar en el futuro un levantamiento de información que permita evaluar las diferencias y similitudes observables a nivel de especialidades entre el currículum "oficial", el currículum efectivamente implementado por los docentes y el adquirido por los alumnos.

Los autores agradecen el financiamiento otorgado por el Ministerio de Educación, mediante el Fondo de Investigación y Desarrollo en Educación (Código Proyecto: FONIDE 143, año 2006) al estudio titulado "La Implementación de la Reforma Curricular en la 
Educación Media Técnico Profesional". Las opiniones que se presentan en esta publicación, así como los análisis e interpretaciones, son de exclusiva responsabilidad de los autores y no reflejan necesariamente la opinión del MINEDUC. De igual forma, se agradecen los valiosos comentarios hechos a distintas versiones previas del estudio por parte de Pamela Márquez, Martín Miranda, Fernando Mena, Esteban Geoffroy y de los evaluadores externos de la revista.

\section{Referencias bibliográficas}

Bunk, Gerhard (1994) La transmisión de las competencias en la formación y perfeccionamiento profesionales en la RFA, Revista CEDEFOP n. ${ }^{\circ} 1$.

Catalano Ana, Avolio Susana, Sladogna Mónica (2004) Competencia Laboral. Diseño curricular basado en normas de competencia laboral. Conceptos y orientaciones metodológicas. Buenos Aires: BID/FOMIN; CINTERFOR.

CINTERFOR (2007) Competencia laboral. Conceptos básicos sobre competencia laboral. Disponible en http://www.ilo.org/public/spanish/region/ampro/ cinterfor/temas/complab/xxxx/esp/i.htm

Descy Pascaline, Tessaring Manfred (2002) Formar y aprender para la competencia profesional. Segundo Informe de la investigación sobre formación profesional en Europa. Resumen ejecutivo, CEDEFOP Reference series n. ${ }^{\circ} 12$. Luxemburgo. Oficina de Publicaciones Oficiales de las Comunidades Europeas.

Ducci, María Angélica (1997) "El enfoque de competencia laboral en la perspectiva internacional". En CINTERFOR/OIT (Editor). Formación basada en competencia laboral. Montevideo, CINTERFOR/OIT.

Gallart, María Antonia y Jacinto, Claudia (1997) "Competencias laborales: tema clave en la articulación educación trabajo". En M.A. Gallart y R. Bertoncello (Editores). Cuestiones actuales de la formación, Montevideo, CINTERFOR/OIT. Papeles de la Oficina Técnica N. ${ }^{\circ} 2$.

Gonzci, Andrew, Athanasou, James (1996) "Instrumentación de la educación basada en competencias. Perspectivas de la teoría y práctica en Australia". En A. Argüelles (Editor). Competencia Laboral y Educación Basada en Normas de Competencia. México, DF: Limusa.

Kochansky, Jim (1998) "El sistema de competencies". En Training and Development Digest, Madrid.

Le Boterf, Guy (2001) La ingeniería de las competencias. Barcelona, España: Editorial Gestión 2000. 
Márquez Pamela, Mena, Fernando, Espinoza, Oscar, Álvarez, Edgardo y otros (2005) Actualización y profundización pedagógica de docentes de educación técnica media y postmedia. Proyecto FONDEF D0211017.

MINEDUC, Unidad de Currículum y Evaluación (2006) Implementación Curricular en la enseñanza media técnico profesional. Estudio cualitativo en profundidad en las especialidades: Administración, Agropecuaria, Mecánica Automotriz y Servicios de Alimentación Colectiva. Santiago. Mineduc.

MINEDUC (2008) Anuario Estadístico 2008. Disponible en http://w3app. Mineduc.cl/Mineduc/ded/documentos/Estadisticas_2008_Capitulo_2. pdf

Miranda, Martín (2003) Transformación de la Educación Media Técnico Profesional.

En C. Cox (editor) Políticas Educacionales en el cambio de siglo. La reforma del sistema escolar chileno. Santiago de Chile. Editorial Universitaria.

Navío, Antonio (2005) Propuestas conceptuales en torno a la competencia profesional. Universidad Autónoma de Barcelona. En Revista de Educación (mayo-agosto), n. ${ }^{\circ} 337$. pp. 213-234.

OCDE (2004) Informe sobre revisión de políticas nacionales de educación. Paris: OCDE.

Recibido: 08/02/2010

Aceptado: 24/05/2010 